\title{
Concordance of skin test reactivity between indoor inhalant allergens among children with allergic respiratory disease
}

Prapasri Kulalert ${ }^{1,2,3,4^{*}}$, Paskorn Sritipsukho ${ }^{2,3,4}$, Sira Nanthapisal ${ }^{2,3,4}$ and Orapan Poachanukoon $n^{2,3,4}$

\begin{abstract}
Background: In vitro studies have demonstrated cross-reactivity among indoor allergen proteins in children with allergic respiratory diseases. However, there are only few studies evaluating in vivo response. A skin prick test (SPT) with commercial indoor solutions is widely used in clinical practice. We aimed to evaluate SPT agreement in children with allergic respiratory disease between pairs of common indoor allergens.

Methods: We reviewed SPT results of children 2 to 18 years old, diagnosed with respiratory allergic disease. Results from house dust mite (Dermatophagoides farinae, Dermatophagoides pteronyssinus), cockroach (Periplaneta americana, Blatella germanica), cat and dog were collected. Sensitization was defined as $\geq 3 \mathrm{~mm}$ in wheal diameter. Kappa coefficient ( $\mathrm{k}$ ) was used to analyze sensitization concordance for each allergen pair.

Results: The charts of 300 children, 187 (62.33\%) males, were reviewed. Mean age was $7.43 \pm 3.29$ years with 183 (61\%), 140 (46.67\%), 45 (15\%), 30 (10\%) sensitizations to house dust mite (HDM), cockroach, cat and dog, respectively. Sensitization concordance between HDM and cockroach was moderate: $\mathrm{k}=0.53$ ( $95 \% \mathrm{Cl}: 0.42-0.64$ ). Moderate agreement occurred between dog and cat: $\mathrm{K}=0.41$ (95\%Cl: 0.30-0.52). HDM-sensitized children showed poor concordance with both cat $\mathrm{K}=0.17$ (95\%Cl: $0.09-0.24)$ and dog $\mathrm{K}=0.09$ (95\%Cl: $0.03-0.14)$. There was also poor concordance between cockroach-sensitized children to cat $\mathrm{K}=0.19$ (95\% $\mathrm{Cl} ; 0.11-0.28)$ and dog $\mathrm{K}=0.11$ (95\%Cl; 0.04-0.18).
\end{abstract}

Conclusion: We demonstrated moderate agreement of SPT response between HDM and cockroach as well as dog and cat. This may be due to cross-reactivity. Component-resolved diagnosis should be considered in children with co-sensitization of these allergen pairs.

Keywords: Asthma, Allergic Rhinitis, Allergens, Skin Tests

\section{Background}

Asthma and allergic rhinitis are common allergic respiratory diseases in children. Exposure to aeroallergens especially indoor allergens are closely linked to sensitization, a significant risk factor for the triggering and persistence of symptoms associated with allergic respiratory diseases [1-3].

\footnotetext{
*Correspondence: prapasrikulalert@gmail.com

1 Department of Clinical Epidemiology, Faculty of Medicine, Thammasat University, Pathumthani 12120, Thailand

Full list of author information is available at the end of the article
}

Indoor allergens are derived from house dust mite (HDM), cockroach and domestic pets. HDM are the most prevalent cause of sensitization worldwide, especially Dermatophagoides farinae and Dermatophagoides pteronyssinus. Cockroach sensitization is second most frequent for children with allergic respiratory diseases, which include American cockroach (Periplaneta americana) and German cockroach (Blattella germanica). Cat and dog present the most notable child pet allergies [3, 4]. In vitro studies have demonstrated cross-reactivity in protein families between arthropod inhalant allergens i.e. 
HDM and cockroach or between mammalian allergens i.e. cat and dog [4-7].

A skin prick test (SPT) is recommended to diagnose allergen sensitization. It is widely used in clinical practice because of its many advantages: easy to perform, fast results, and low cost [8]. Extracts from Dermatophagoides farinae, Dermatophagoides pteronyssinus Periplaneta americana, Blattella germanica, cat and dog are readily available.

However, there has been few studies evaluating the correlation of skin test responses among indoor allergens. In our opinion, it would be useful to obtain more comprehensive data evaluating indoor allergen SPT results among children with allergic respiratory diseases. Our hypothesis is SPT response concordance may be associated with cross-reactivity among protein family allergens. The objective of this study was to evaluate the concordance of skin test response between the pairs of indoor allergens among children with allergic respiratory diseases.

\section{Methods}

This was a retrospective medical chart review of children, 2 to 18 years old, diagnosed with allergic rhinitis and/or asthma having undergone SPT at the Pediatric Allergy Clinic of Thammasat University Hospital, Pathum Thani Province, Thailand, from January 2015 to January 2017.

\section{Data collection}

Data on patient age when performed SPT, gender and diagnosis were collected. SPT results for 6 extracts, include, Dermatophagoides farinae 10,000 AU/mL, Dermatophagoides pteronyssinus 10,000 AU/mL, American cockroach 1:20 w/v, German cockroach 1:20 w/v, Dog epithelium 1:20 w/v, and Standardized cat hair $10,000 \mathrm{BAU} / \mathrm{mL}$. Histamine $1 \mathrm{mg} / \mathrm{mL}$ and $50 \%$ Glycerine were used as positive and negative control. All SPT solutions were obtained from ALK-Abelló, Port Washington, New York, USA. All patients had SPT on the volar of the forearm using lancets by a team of experienced nurses with each patient having the same nurse and all extracts in the same time. Readings were performed 15-20 min after SPT. Wheal size was measured by the longest and orthogonal diameters, reported as millimeters $(\mathrm{mm})$.

\section{Definition of outcome}

Sensitization was defined as when the wheal diameter was $\geq 3 \mathrm{~mm}$ than that of the negative control. HDM sensitization was defined as a positive to SPT result for Dermatophagoides farinae and/or Dermatophagoides pteronyssinus. Cockroach sensitization was defined as positive SPT result for American cockroach and/or German cockroach.

\section{Statistical analysis}

Demographic characteristics were presented as mean \pm SD for continuous variables and as \% for categorical variables. Prevalence of sensitization was reported as frequency (\%). Sensitization agreement for each allergen pair used kappa coefficient ( $\mathrm{k}$ ) for analysis: $\mathrm{K}<0.00$ was considered poor strength of agreement; к: $0.00-0.20$ slight strength; к: $0.21-0.40$ fair; к: 0.41 - 0.60 moderate; к: $0.61-0.80$ substantial; and к: 0.81 - 1.00 almost perfect agreement [9].

\section{Sample size calculation}

Sample size was estimated using power analysis for a one sample proportion test in Stata v15.1. We hypothesized moderate agreement for skin test response between pairs of cross-reactivity protein family allergens. Thus, $\mathrm{K}$ was estimated 0.5 with probably not expected to have deviated more than 0.1 . The number of population that must be used at least was 259 participants for providing the $90 \%$ power, $\alpha=0.05$ and twoside test.

\section{Results}

The medical charts of 300 patients were reviewed. Mean age was $7.43 \pm 3.29$ years; $187(62.33 \%)$ were males, and 113 were females (37.67\%). Two hundred and sixteen (72.0\%) patients were diagnosed with allergic rhinitis alone, and 13 patients $(4.33 \%)$ were diagnosed with asthma alone. Seventy-one patients $(23.67 \%)$ had both allergic rhinitis and asthma. In all, 183 (61.00\%) patients

Table 1 Patient demographics $(N=300)$

\begin{tabular}{ll}
\hline Characteristics & N (\%) \\
\hline Age (mean \pm SD in years) & $7.43 \pm 3.29$ \\
Gender & $187(62.33)$ \\
Male & $113(37.67)$ \\
Female & \\
Diagnosis & $216(72.00)$ \\
Allergic rhinitis only & $71(23.67)$ \\
Allergic rhinitis with asthma & $13(4.33)$ \\
Asthma only & \\
Skin test sensitization & $183(61.00)$ \\
House dust mite & $140(46.67)$ \\
Cockroach & $45(15.00)$ \\
Cat hair & $30(10.00)$ \\
Dog epithelium &
\end{tabular}


were sensitized to HDM, 140 (46.67\%) were sensitized to cockroach, 45 (15.00\%) were sensitized to cat hair, and 30 (10.00\%) were sensitized to dog epithelium (Table 1).

\section{Co-sensitization and concordance of SPT reactivity to indoor allergens}

Results showed in Tables 2 and 3, which describe the concordance of SPT responses between each allergen pair. There were 126/183 (68.85\%) patients who were sensitized to HDM having co-sensitization with cockroach. One hundred and twenty-six (126) HDMsensitized patients had cockroach sensitization: cosensitization was $90 \%$. SPT responses between HDM and cockroach had a moderate agreement, $\mathrm{\kappa}=0.53$ (95\%CI: 0.42 to 0.64 ).

In contrast, $22.95 \%$ (42/183 patients) of those with sensitization to HDM also had sensitization to cat hair, while $14.21 \%(26 / 183)$ had sensitization to dog epithelium. Thus, concordance of SPT responses between HDM and all pet allergens tested were poor: $\mathrm{K}=0.17$ (95\%CI: 0.09 to 0.24 ) for cat hair and 0.09 (95\%CI; 0.03 to 0.14 ) for dog epithelium. Only $25 \%$ (35/140 patients) of those with cockroach sensitization had cat hair sensitization, and $15.71 \%(22 / 140)$ were sensitized to dog dander. This also showed a poor agreement in SPT responses between cockroach and cat hair: $\mathrm{k}=0.19$ (95\% CI: 0.11 to 0.28 ) as well as between cockroach and dog epithelium: $\kappa=0.11$ (95\%CI: 0.04 to 0.18 ).

Among patients sensitized to pet allergens, 40\% of the children (18/45) with cat hair sensitization showed coexistence with dog epithelium sensitization. Around 60\% (18/30) with dog epithelium sensitization showed cat hair sensitization, too. Concordance of SPT responses between cat and dog were moderate: $\kappa=0.41$ (95\% CI: 0.30 to 0.52 ).

\section{Discussion}

Our study showed HDM to be the most common indoor allergen sensitization, followed by cockroach, cat and dog. This pattern of indoor allergen sensitization has not appeared to change over time as our results are similar to previous studies for children living in Thailand $[10,11]$ and other Asian countries [3].

Dermatophagoides farinae (Der f) and Dermatophagoides pteronyssinus (Der p) were common sensitization in Thai atopic patients $[11,12]$ and were the most identified from house dust samples [13]. Blomia tropicalis (Blo $t$ ) predominantly found in tropical and subtropical regions [14]. However, a previous study indicated that Blo $t$ was rarely found in Thailand [13]. Previous study reported low prevalence of Blo $t$ sensitization and all patients with sensitized to Blomia troplicalis extracts were sensitized to Dermatophagoides [12].

Cockroach is the second most common aeroallergen sensitization. Our study was evident in $46.67 \%$. The prevalence of cockroach sensitization varies in different countries.

The high sensitization rate was found in Brazil 57.5\% [15], Africa (55\%) [16], Taiwan (50.7\%) [17], and US (42\%) [18]. In contrast, this prevalence was higher than that found in other Asian countries e.g. Hong Kong (33\%) [19], China (24.3\%) [20], Korea (23.6\%) [21], India (18.3\%) [22], and Vietnam (13.1\%) [23], respectively. Our sensitization rate was also higher than European countries e.g. Poland (25\%) [24] and Spain (15\%) [25].

Table 2 Indoor allergen co-sensitization frequencies

\begin{tabular}{|c|c|c|c|c|}
\hline \multirow[t]{2}{*}{ Patient sensitization } & \multicolumn{4}{|c|}{ Number of patients with co-sensitization, $\mathrm{N}(\%)$} \\
\hline & House dust mite & Cockroach & Cat hair & Dog epithelium \\
\hline House dust mite $(\mathrm{N}=183)$ & - & $126(68.85)$ & $42(22.95)$ & $26(14.21)$ \\
\hline Cockroach $(\mathrm{N}=140)$ & $126(90.00)$ & - & $35(25.00)$ & $22(15.71)$ \\
\hline Cat hair $(\mathrm{N}=45)$ & $42(93.33)$ & $35(77.78)$ & - & $18(40.00)$ \\
\hline Dog epithelium $(\mathrm{N}=30)$ & $26(86.67)$ & $22(73.33)$ & $18(60.00)$ & - \\
\hline
\end{tabular}

Table 3 Skin test responses agreements between indoor allergen pairs

\begin{tabular}{|c|c|c|c|c|}
\hline \multirow[t]{2}{*}{ Allergen } & \multicolumn{4}{|l|}{ Kappa (95\% Cl) } \\
\hline & House dust mite & Cockroach & Cat hair & Dog epithelium \\
\hline House dust mite & - & 0.53 (0.42 to 0.64$)$ & 0.17 (0.09 to 0.24 ) & 0.09 (0.03 to 0.14 ) \\
\hline Cockroach & - & - & 0.19 (0.11 to 0.28$)$ & 0.11 (0.04 to 0.18 ) \\
\hline Cat hair & - & - & - & 0.41 (0.30 to 0.52 ) \\
\hline
\end{tabular}


Cockroach exposure has been linked to cockroach sensitization [26]. The levels of cockroach allergens measure in the home are strongly associated with a greater risk for the development of cockroach sensitization [27, 28]. In Thailand, Tungtrongchitr A et al. found that cockroach allergens of the predominant species, Periplaneta Americana, were detected in all households of allergic patients, with the highest level in the kitchen areas. The mean allergen level in kitchen dust were $62.8 \mu \mathrm{g}$ per g of dust [29]. This may potential for development of cockroach sensitization.

We had a high proportion of co-sensitization between HDM and cockroach. This is also similar to prior researches. Uzel A, et al. [30] reported $73.9 \%$ of adults with cockroach sensitivity had reactivity to HDM. An evaluation by Macan J, et al. stated positive SPT to HDM denoted significantly increased risks for reactivity to cockroach [31]. Moreover, a large cohort study $(\mathrm{N}=5,782)$ confirmed the association between sensitization to cockroach and mite was strong, $71 \%$ of those with a positive SPT to cockroach also had a positive SPT to any mite. Conversely, of mite-sensitized subjects $36 \%$ were also sensitized to cockroach [23]. However, these previous studies did not evaluate the level of agreement in pair allergens i.e. SPT responses between HDM and cockroach allergens. Our study is the first publication to do so, demonstrating moderate agreement.

The rationale of agreement for skin test reactivity between HDM and cockroach could be explained by protein family cross-reactivity sharing epitopes e.g. tropomyosin [32]. Studies reported Group 10 allergenic tropomyosin found in $\operatorname{HDM}[4,5]$, namely, dermatophagoides farinae (Der f 10) and dermatophagoides pteronyssinus (Der p 10). Cockroach found allergenic tropomyosin in periplaneta americana (Per a7), blattella germanica (Blag7) [6].

Sun BQ et al. [33] reported $88 \%$ of positive SPT to cockroach patients were also positive SPT to HDM. An IgE cross-inhibition study confirmed that Der p sensitization may cause false positive SPT reactions against cockroach.

Allergen extracts from HDMs are frequently of poor quality. The use of purified recombinant allergens for diagnostic purposes may therefore be considered as an alternative, or even an improvement over the traditional allergen extracts [34] Weghofer et al. reported $10-18 \%$ of mite allergic patients in Europe had IgE-reactivity to Der p 10 (mite tropomyosin). Westritschnig et al. [35] demonstrated that $55 \%$ of African patients had Der p 10 (mite tropomyosin) sensitization which are higher than European study.

Diagnosis of cockroach allergy is performed using crude extracts by in vivo skin testing and/or in vitro measurement of specific IgE to cockroach (by ImmunoCAP). Cockroach extracts are non-standardized, highly variable in allergen content and show low potency. Recombinant cockroach allergens have been successfully used for assessment of sensitization [36]. The high frequency of reactivity to cockroach tropomyosin seen in Brazil could reflect cross-reactivity to mite tropomyosin, which shares $80 \%$ sequence identity to the cockroach homolog [37].

In addition, tropomyosin represents a cross-reactive allergen also found in crustaceans (e.g. shrimp, lobster, crab), and helminths [38-41]. However, we did not evaluate the association between respiratory indoor allergens with crustaceans and helminths. Further research is needed.

Cats and dogs are the most prevalent household pets [42]. Pet ownership and animal allergen exposure was associated with corresponding allergic sensitization [4345]. The prevalence of sensitization to cats and dogs of our study were low (15\% for cat and $10 \%$ for dog). Our results are consistent with a previous study [11]. Sritipsukho et al. reported the low prevalence of pet sensitization (13\% for cat and $8 \%$ for dog) and low prevalence $(20 \%)$ of pet ownership in our country. We assumed the low prevalence of pet ownership may be causing of the low sensitization to pets allergen.

We noted moderate SPT concordance between cat and dog. The co-sensitization to dog was $60 \%$ among patients sensitized to cat. Sixty-eight of 109 patients (62\%) with animal allergy showed IgE reactivity to cat allergens and dog allergens [46]. To date, molecular diagnosis is strongly recommended performing in polysensitized patients to distinguishing between sensitizations specific to singular species and sensitizations due to cross-reactivity [47]. The frequency of co-sensitization with cat and dog may be explained by shared proteins between the two species e.g. lipocalins, or serum albumins. Four dog allergens (e.g. Can f 1, Can f 2, Can f 4, and Can f 6) and two cat allergens (Fel d 4 and Fel d 7) are in the lipocalins family of proteins.

Studies have shown lipocalins are responsible for allergenic protein cross-reactivity between cat and dog dander. Smith W et al. found that Fel $d 7$ binds IgE in 38\% of cat allergic individuals. Fel $\mathrm{d} 7$ share $62 \%$ sequence identity with Can $\mathrm{f} 1$ and may suggest a molecular mechanism of cross-reactivity and cosensitization [48].

Can $\mathrm{f} 6$ showed cross-reactivity with Fel d4. sIgE to Can $\mathrm{f} 6$ is present in $38 \%$ of patients sensitized to dogs; however, it appears in $60 \%$ of patients sensitized to both cats and dogs, which could be related to its identity with Fel d 4 [49]. In addition, albumins are minor allergens. Allergenic serum albumins also include Can f3 (Dog) and Fel d2 (Cat) [50]. 
Moreover, Cat and dog may be sensitized to other animals e.g. horse. Some lipocalins have amino acid sequences with up to $60 \%$ identity, which explains the cross-reactivity between them, for example, Can $\mathrm{f} 6$ (dog), Equ c 1 (horse), Fel d 4 (cat), Ory c 4 (rabbit), Mus m 1 (mouse), Rat $n 1$ (rat) [51]. The further study should be explore the association of these mamal animals.

Apart from that, we must point out causing co-sensitization as well as from co-exposure. Studies detected multiple indoor allergens, e.g. Der f1, Der p1, Bla g1, Can f1, Fel d1, etc., form dust sample of the participant's home [52, 53]. Co-sensitization among indoor allergens is related to the exposure of multiple indoor allergens in house environment. Therefore, concordance of SPT results of indoor allergens may be due to their cross-relativities.

Identification of allergen sensitization remains important for education on allergen avoidance and must be considered in specific allergen immunotherapy. In routine practice, SPT with indoor allergen extracts is the primary tool for detecting sensitization, and allergen avoidance for all sensitized allergens is always recommended. We demonstrate clear SPT response agreement between certain indoor allergens with shared protein families.

Recently, Component-resolved diagnosis (CRD) has been emerged, which is based on the determination of serum IgE concentration against individual components of the allergen. CRD is potential for distinguishing true allergens from cross-reactive allergen molecules [54]. Several studies have shown the usefulness of CRD in allergy to furry animals, mites and arthropods [55-57].

Best on our knowledge, our study is the first publication showed in vivo evidence of the agreement between the pairs of indoor allergens among children with allergic respiratory diseases. These implications emphasize physicians should consider more specific testing in those with co-sensitization between HDM and cockroach as well as cat and dog dander; this would render a more accurate diagnosis and exclude possible cross-reactivity. The limitation of our study, we should note our researchers reviewed retrospective charts lacking clinical severity data when SPT were performed, making them unable to evaluate the exact relationship between co-sensitization concordance and disease severity or the intensity of the wheal diameter with clinical relevance. As such, it would helpful for further studies to be prospective.

\section{Conclusion}

Our study showed moderate concordance of SPT between HDM and cockroach as well as between dog and cat, most likely due to cross-reactivity, or possibly parallel sensitization. CRD should be considered in children with co-sensitization of these allergen pairs.

\section{Abbreviations}

SPT: Skin prick test; CRD: Component-resolved diagnosis; HDM: House Dust Mite.

\section{Acknowledgements \\ We would like to thank Ms Debra Kim Liwiski, writer/international instructor, Clinical Research Center, Faculty of Medicine, for language editing.}

\section{Authors' contributions}

Conceptualization, P.K and P.S.; methodology, P.K. and P.S.; validation, P.K. and P.S; formal analysis, P.K.; data curation, P.K., S.N., O.P, and P.S.; writing-original draft preparation, P.K.; writing — review and editing, S.N., O.P. and P.S.; visualization, P.K. All authors have read and agreed to the published version of the manuscript. The author (s) read and approved the final manuscript.

\section{Funding}

This study was funded by Faculty of medicine, Thammasat University.

Availability of data and materials

The dataset analyzed in the current study is available from the corresponding author on reasonable request.

\section{Declarations}

\section{Ethics approval and consent to participate}

This study was approved by The Institutional Review Board and the Ethics Committee of Faculty of Medicine, Thammasat University (MTU-ECPE-6-014/60) and was performed in accordance with the relevant guidelines and regulations (Declaration of Helsinki). The need for informed consent was waived by the Ethics Committee of Faculty of Medicine, Thammasat University due to the retrospective nature of the study.

\section{Consent for publication}

Not applicable.

\section{Competing interests}

The authors declare that they have no competing interests.

\section{Author details}

${ }^{1}$ Department of Clinical Epidemiology, Faculty of Medicine, Thammasat University, Pathumthani 12120, Thailand. ${ }^{2}$ Division of Allergy and Immunology, Department of Pediatrics, Faculty of Medicine, Thammasat University, Pathumthani, Thailand. ${ }^{3}$ Center of Excellence in Applied Epidemiology, Thammasat University, Pathumthani, Thailand. ${ }^{4}$ Center of Excellence for Allergy, Asthma and Pulmonary Disease, Thammasat University, Pathumthani, Thailand.

Received: 3 February 2021 Accepted: 15 July 2021

Published online: 11 August 2021

\section{References}

1. Kanchongkittiphon W, Mendell MJ, Gaffin JM, Wang G, Phipatanakul W. Indoor environmental exposures and exacerbation of asthma: an update to the 2000 review by the Institute of Medicine. Environ Health Perspect. 2015;123(1):6-20.

2. Sheehan WJ, Phipatanakul W. Indoor allergen exposure and asthma outcomes. Curr Opin Pediatr. 2016;28(6):772-7.

3. Tham EH, Lee AJ, Bever HV. Aeroallergen sensitization and allergic disease phenotypes in Asia. Asian Pac J Allergy Immunol. 2016;34(3):181-9.

4. Pomés A, Chapman MD, Wünschmann S. Indoor Allergens and Allergic Respiratory Disease. Curr Allergy Asthma Rep. 2016;16(6):43.

5. Raulf M, Bergmann KC, Kull S, Sander I, Hilger C, Brüning T, et al. Mites and other indoor allergens - from exposure to sensitization and treatment. Allergo J Int. 2015;24(3):68-80.

6. Hilger C, Kuehn A, Raulf M, Jakob T. Cockroach, tick, storage mite and other arthropod allergies: Where do we stand with molecular allergy 
diagnostics?: Part 15 of the Series Molecular Allergology. Allergo J Int. 2014;23(6):172-8.

7. Nilsson $\mathrm{OB}$, van Hage $\mathrm{M}$, Grönlund H. Mammalian-derived respiratory allergens - implications for diagnosis and therapy of individuals allergic to furry animals. Methods. 2014;66(1):86-95.

8. Bousquet J, Heinzerling L, Bachert C, Papadopoulos NG, Bousquet PJ, Burney $\mathrm{PG}$, et al. Practical guide to skin prick tests in allergy to aeroallergens. Allergy. 2012;67(1):18-24.

9. McHugh ML. Interrater reliability: the kappa statistic. Biochem Med (Zagreb). 2012;22(3):276-82.

10. Yuenyongviwat A, Koonrangsesomboon D, Sangsupawanich P. Recent 5 -year trends of asthma severity and allergen sensitization among children in southern Thailand. Asian Pac J Allergy Immunol. 2013;31(3):242-6.

11. Sritipsukho P. Aeroallergen sensitivity among Thai children with allergic respiratory diseases: a hospital-based study. Asian Pac J Allergy Immunol. 2004;22(2-3):91-5.

12. Daengsuwan T, Lee BW, Visitsuntorn N, Charoenratanakul S, Ruangrak S, Jirapongsananuruk $\mathrm{O}$, et al. Allergen sensitization to aeroallergens including Blomia tropicalis among adult and childhood asthmatics in Thailand. Asian Pac J Allergy Immunol. 2003;21(4):199-204.

13. Malainual N, Vichyanond P, Phan-Urai P. House dust mite fauna in Thailand. Clin Exp Allergy. 1995;25(6):554-60.

14. Calderón MA, Linneberg A, Kleine-Tebbe J, De Blay F, Hernandez Fernandez de Rojas D, Virchow JC, et al. Respiratory allergy caused by house dust mites: What do we really know? J Allergy Clin Immunol. 2015;136(1):38-48.

15. Silva JM, Camara AA, Tobias KR, Macedo IS, Cardoso MR, Arruda E, et al. A prospective study of wheezing in young children: the independent effects of cockroach exposure, breast-feeding and allergic sensitization. Pediatr Allergy Immunol. 2005;16(5):393-401.

16. Oluwole O, Arinola OG, Falade GA, Ige MO, Falusi GA, Aderemi T, et al. Allergy sensitization and asthma among 13-14 year old school children in Nigeria. Afr Health Sci. 2013;13(1):144-53.

17. Lan JL, Lee DT, Wu CH, Chang CP, Yeh CL. Cockroach hypersensitivity: preliminary study of allergic cockroach asthma in Taiwan. J Allergy Clin Immunol. 1988:82(5 Pt 1):736-40.

18. Min K, Yoshida M, Miike R, Tam E. Aeroallergen sensitivity in Hawai'í: association with asthma and increased prevalence of sensitivity to indoor allergens since 1966. Hawaii J Med Public Health. 2014;73(9 Suppl 1):9-12.

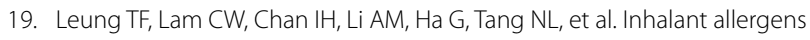
as risk factors for the development and severity of mild-to-moderate asthma in Hong Kong Chinese children. J Asthma. 2002;39(4):323-30.

20. Luo W, Hu H, Tang W, Zou X, Huang H, Huang Z, et al. Allergen sensitization pattern of allergic adults and children in southern China: a survey based on real life data. Allergy Asthma Clin Immunol. 2019;15:42.

21. Park HJ, Lee JH, Park KH, Ann HW, Jin MN, Choi SY, et al. A nationwide survey of inhalant allergens sensitization and levels of indoor major allergens in Korea. Allergy Asthma Immunol Res. 2014;6(3):222-7.

22. Raj D, Lodha R, Pandey A, Mukherjee A, Agrawal A, Kabra SK. Aeroallergen sensitization in childhood asthmatics in northern India. Indian Pediatr. 2013;50(12):1113-8.

23. Lâm HT, Ekerljung L, Bjerg A, Văn TTN, Lundbäck B, Rönmark E. Sensitization to airborne allergens among adults and its impact on allergic symptoms: a population survey in northern Vietnam. Clin Transl Allergy. 2014;4(1):6.

24. Stelmach I, Jerzynska J, Stelmach W, Majak P, Chew G, Gorski P, et al. Cockroach allergy and exposure to cockroach allergen in Polish children with asthma. Allergy. 2002;57(8):701-5.

25. Pola J, Valdivieso R, Zapata C, Moneo I, Duce F, Larrad L, et al. Cockroach hypersensitivity in asthmatic patients. Allergol Immunopathol (Madr). 1988;16(2):105-7.

26. Do DC, Zhao Y, Gao P. Cockroach allergen exposure and risk of asthma. Allergy. 2016;71(4):463-74.

27. Chew GL, Perzanowski MS, Canfield SM, Goldstein IF, Mellins RB, Hoepner $L A$, et al. Cockroach allergen levels and associations with cockroachspecific IgE. J Allergy Clin Immunol. 2008;121(1):240-5.

28. Olmedo O, Goldstein IF, Acosta L, Divjan A, Rundle AG, Chew GL, et al. Neighborhood differences in exposure and sensitization to cockroach, mouse, dust mite, cat, and dog allergens in New York City. J Allergy Clin Immunol. 2011;128(2):284-92.e7.
29. Tungtrongchitr A, Sookrung N, Munkong N, Mahakittikun V, Chinabut P, Chaicumpa W, et al. The levels of cockroach allergen in relation to cockroach species and allergic diseases in Thai patients. Asian Pac J Allergy Immunol. 2004;22(2-3):115-21.

30. Uzel A, Capan N, Canbakan S, Yurdakul AS, Dursun B. Evaluation of the relationship between cockroach sensitivity and house-dust-mite sensitivity in Turkish asthmatic patients. Respir Med. 2005;99(8):1032-7.

31. Macan J, Plavec D, Kanceljak B, Milkovic-Kraus S. Exposure levels and skin reactivity to German cockroach (Blattella germanica) in Croatia. Croat Med J. 2003:44(6):756-60

32. Reese G, Ayuso R, Lehrer SB. Tropomyosin: an invertebrate pan-allergen. Int Arch Allergy Immunol. 1999;119(4):247-58.

33. Sun BQ, Lai XX, Gjesing B, Spangfort MD, Zhong NS. Prevalence of sensitivity to cockroach allergens and lgE cross-reactivity between cockroach and house dust mite allergens in Chinese patients with allergic rhinitis and asthma. Chin Med J (Engl). 2010;123(24):3540-4.

34. Weghofer M, Thomas WR, Kronqvist M, Mari A, Purohit A, Pauli G, et al. Variability of IgE reactivity profiles among European mite allergic patients. Eur J Clin Invest. 2008;38(12):959-65.

35. Westritschnig K, Sibanda E, Thomas W, Auer H, Aspöck H, Pittner G, et al. Analysis of the sensitization profile towards allergens in central Africa. Clin Exp Allergy. 2003;33(1):22-7.

36. Pomés A, Mueller GA, Randall TA, Chapman MD, Arruda LK. New Insights into Cockroach Allergens. Curr Allergy Asthma Rep. 2017;17(4):25.

37. Arruda LK, Barbosa MC, Santos AB, Moreno AS, Chapman MD, Pomés A. Recombinant allergens for diagnosis of cockroach allergy. Curr Allergy Asthma Rep. 2014;14(4):428.

38. Arruda LK, Santos AB. Immunologic responses to common antigens in helminthic infections and allergic disease. Curr Opin Allergy Clin Immunol. 2005;5(5):399-402.

39. Asturias JA, Eraso E, Moneo I, Martínez A. Is tropomyosin an allergen in Anisakis? Allergy. 2000;55(9):898-9.

40. Santiago HC, Bennuru S, Boyd A, Eberhard M, Nutman TB. Structural and immunologic cross-reactivity among filarial and mite tropomyosin: implications for the hygiene hypothesis. J Allergy Clin Immunol. 2011;127(2):479-86

41. Santos AB, Rocha GM, Oliver C, Ferriani VP, Lima RC, Palma MS, et al. Cross-reactive lgE antibody responses to tropomyosins from Ascaris lumbricoides and cockroach. J Allergy Clin Immunol. 2008;121(4):1040-6.e1.

42. Chan SK, Leung DYM. Dog and Cat Allergies: Current State of Diagnostic Approaches and Challenges. Allergy Asthma Immunol Res. 2018;10(2):97-105.

43. Schäfer T, Stieger B, Polzius R, Krauspe A. Associations between cat keeping, allergen exposure, allergic sensitization and atopic diseases: results from the Children of Lübeck Allergy and Environment Study (KLAUS). Pediatr Allergy Immunol. 2009;20(4):353-7.

44. Chen CM, Rzehak P, Zutavern A, Fahlbusch B, Bischof W, Herbarth $\mathrm{O}$, et al. Longitudinal study on cat allergen exposure and the development of allergy in young children. J Allergy Clin Immunol. 2007;119(5):1148-55.

45. Li C, Chen Q, Zhang X, Li H, Liu Q, Fei P, et al. Early Life Domestic Pet Ownership, and the Risk of Pet Sensitization and Atopic Dermatitis in Preschool Children: A Prospective Birth Cohort in Shanghai. Front Pediatr. 2020;8:192.

46. Spitzauer S, Pandjaitan B, Mühl S, Ebner C, Kraft D, Valenta R, et al. Major cat and dog allergens share lgE epitopes. J Allergy Clin Immunol. 1997;99(1 Pt 1):100-6.

47. Dávila I, Domínguez-Ortega J, Navarro-Pulido A, Alonso A, Antolín-Amerigo D, González-Mancebo E, et al. Consensus document on dog and cat allergy. Allergy. 2018;73(6):1206-22.

48. Smith W, O'Neil SE, Hales BJ, Chai TL, Hazell LA, Tanyaratsrisakul S, et al. Two newly identified cat allergens: the von Ebner gland protein Fel $\mathrm{d} 7$ and the latherin-like protein Fel d 8. Int Arch Allergy Immunol. 2011;156(2):159-70.

49. Nilsson OB, Binnmyr J, Zoltowska A, Saarne T, van Hage M, Grönlund H. Characterization of the dog lipocalin allergen Can $\mathrm{f} 6$ : the role in crossreactivity with cat and horse. Allergy. 2012;67(6):751-7.

50. Cabañas R, López-Serrano MC, Carreira J, Ventas P, Polo F, Caballero MT, et al. Importance of albumin in cross-reactivity among cat, dog and horse allergens. J Investig Allergol Clin Immunol. 2000;10(2):71-7. 
51. Hentges F, Léonard C, Arumugam K, Hilger C. Immune responses to inhalant Mammalian allergens. Front Immunol. 2014;5:234.

52. Moghtaderi M, Farjadian S, Fereidouni M, Nasiri M, Nejat A. Indoor Dust Allergen Levels in the Homes of Patients with Childhood Asthma: An Experience From Southwestern Iran. Iran J Allergy Asthma Immunol. 2016;15(2):132-7.

53. Salo PM, Wilkerson J, Rose KM, Cohn RD, Calatroni A, Mitchell HE, et al. Bedroom allergen exposures in US households. J Allergy Clin Immunol. 2018:141(5):1870-9.e14.

54. Matricardi PM, Kleine-Tebbe J, Hoffmann HJ, Valenta R, Hilger C, Hofmaier $\mathrm{S}$, et al. EAACI Molecular Allergology User's Guide. Pediatr Allergy Immunol. 2016;27(Suppl 23):1-250.

55. Curin M, Swoboda I, Wollmann E, Lupinek C, Spitzauer S, van Hage M, et al. Microarrayed dog, cat, and horse allergens show weak correlation between allergen-specific IgE and IgG responses. J Allergy Clin Immunol. 2014;133(3):918-21.e6.

56. Bjerg A, Winberg A, Berthold M, Mattsson L, Borres MP, Rönmark E. A population-based study of animal component sensitization, asthma, and rhinitis in schoolchildren. Pediatr Allergy Immunol. 2015;26(6):557-63.

57. Mohamad Yadzir ZH, Misnan R, Abdullah N, Bakhtiar F, Leecyous B, Murad S. Component-resolved diagnosis (CRD): Is it worth it? frequency and differentiation in rhinitis patients with mite reactivity. Iran J Allergy Asthma Immunol. 2014;13(4):240-6.

\section{Publisher's Note}

Springer Nature remains neutral with regard to jurisdictional claims in published maps and institutional affiliations.
Ready to submit your research? Choose BMC and benefit from:

- fast, convenient online submission

- thorough peer review by experienced researchers in your field

- rapid publication on acceptance

- support for research data, including large and complex data types

- gold Open Access which fosters wider collaboration and increased citations

- maximum visibility for your research: over 100M website views per year

At BMC, research is always in progress.

Learn more biomedcentral.com/submissions 